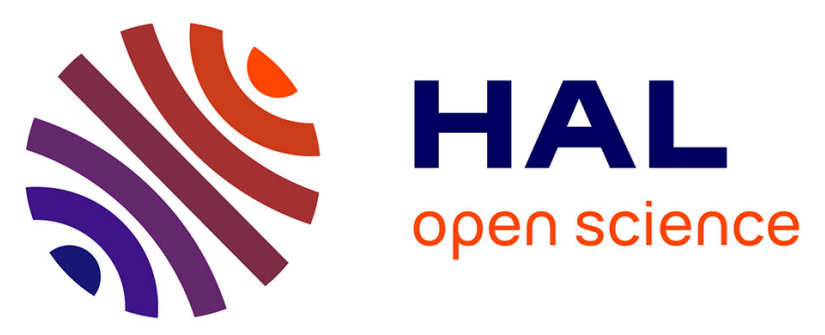

\title{
A multilayer model for describing hardness variations of aged porous silicon low-dielectric-constant thin films
}

Kahdija Rahmoun, Alain Iost, Vincent Keryvin, Gildas Guillemot, N.-E. Chabane Sari

\section{- To cite this version:}

Kahdija Rahmoun, Alain Iost, Vincent Keryvin, Gildas Guillemot, N.-E. Chabane Sari. A multilayer model for describing hardness variations of aged porous silicon low-dielectric-constant thin films. Thin Solid Films, 2009, 518 (1), pp.213-221. 10.1016/j.tsf.2009.07.040 . hal-01170940

\author{
HAL Id: hal-01170940 \\ https://hal.science/hal-01170940
}

Submitted on 8 Jul 2015

HAL is a multi-disciplinary open access archive for the deposit and dissemination of scientific research documents, whether they are published or not. The documents may come from teaching and research institutions in France or abroad, or from public or private research centers.
L'archive ouverte pluridisciplinaire HAL, est destinée au dépôt et à la diffusion de documents scientifiques de niveau recherche, publiés ou non, émanant des établissements d'enseignement et de recherche français ou étrangers, des laboratoires publics ou privés. 


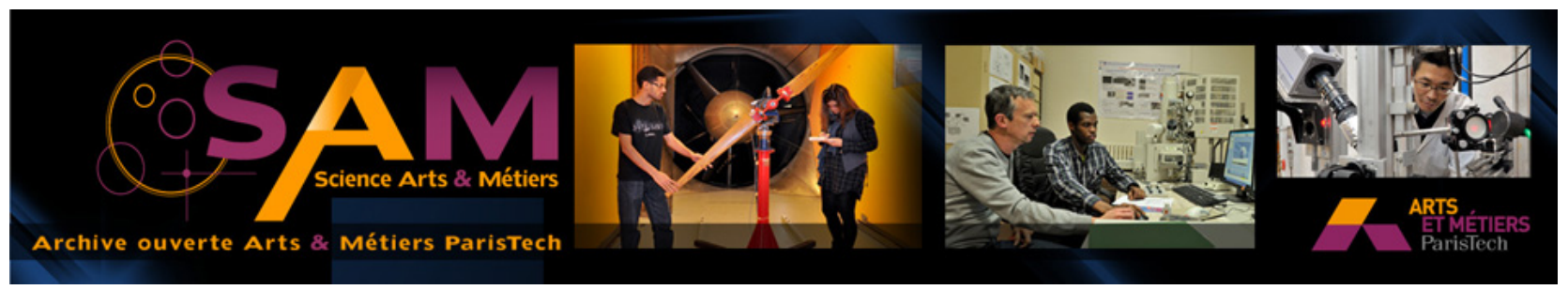

\section{Science Arts \& Métiers (SAM)}

is an open access repository that collects the work of Arts et Métiers ParisTech researchers and makes it freely available over the web where possible.

This is an author-deposited version published in: http://sam.ensam.eu

Handle ID: .http://hdl.handle.net/10985/9696

\section{To cite this version :}

Kahdija RAHMOUN, Alain IOST, Vincent KERYVIN, Gildas GUILLEMOT, SARI CHABANE - A multilayer model for describing hardness variations of aged porous silicon low-dielectric-constant thin films - Thin Solid Films - Vol. 518, n¹, p.213-221 - 2009 


\title{
A multilayer model for describing hardness variations of aged porous silicon low-dielectric-constant thin films
}

\author{
K. Rahmoun ${ }^{a}$, A. Iost ${ }^{\text {b, }}$, V. Keryvin ${ }^{c}$, G. Guillemot ${ }^{\text {b }}$, N.E. Chabane Sari ${ }^{\text {a }}$ \\ a Unité de Recherche Matériaux et Energies Renouvelables URMER, Université Abou Bakr Belkaid, BP 119, Tlemcen 13000, Algérie \\ ${ }^{\mathrm{b}}$ Arts et Metiers ParisTech, CNRS, LMPGM, Equipe Caractérisation et Propriétés de la Périsurface, 8 boulevard Louis XIV 59046 Lille Cedex, France \\ c LARMAUR, EA 410, Université de Rennes 1, Campus de Beaulieu, 35042 Rennes cedex, France
}

\section{Keywords:}

Instrumented-indentation testing

Composite hardness modelling

Porous Si film

Low- $k$ dielectric thin film

Martens hardness

\begin{abstract}
A B S T R A C T
This paper reports on the micro-instrumented indentation of a porous silicon structure obtained by anodization of a highly $\mathrm{p}^{+}$-doped (100) silicon substrate aged over 1 week. The three-layer structure obtained consists of oxidized porous silicon (cap-layer), porous silicon (inner-layer) and silicon substrate. The hardness curve has the typical "U shape" of low-dielectric-constant films when the indentation depth rises: the early decrease in hardness, due to the soft inner layer, is followed by an increase, due to the hard substrate. A multilayer model is developed to account for hardness variation with respect to the applied load. This model considers the crumbling of the cap-layer and of the inner porous structure. As a result, it is shown that considering the minima in the $U$ shape gives an over-estimated value when it comes to assessing the coating hardness. In our experiment, this minimum depends on both the hardness and the thickness of the oxidized cap layer, but not on the mechanical properties of the substrate, even for indentation depths slightly lower than the film's thickness.
\end{abstract}

\section{Introduction}

Porous silicon structures are usually processed by electrolytic anodization in ethanol diluted HF solutions. They have been extensively studied since their discovery by Uhlir [1] and Turner [2] in the 1950's and, particularly, since the discovery in 1990 of the strong and visible photoluminescence phenomenon by Canham [3]. The full insulation by porous oxidized silicon technology was the principal exploitation of porous silicon until the discovery of photoluminescence. Applications of porous silicon (PS) in technological fields now include biochemical or gas sensors, optoelectronic devices, micromachining, photovoltaic devices or electric and thermal insulation.

In semiconductor processing, a low- $k$ dielectric material has a low dielectric constant compared to silicon dioxide $(k<4)$. The implementation of low- $k$ dielectric materials is one of several strategies used to allow continuous scaling of microelectronic devices. In digital circuits, insulating dielectrics separate the conducting parts (wire interconnects and transistors) from one another.

The dielectric constant of air at room temperature is 1.00054; therefore the dielectric constant of the porous material can be reduced by increasing the porosity of the film. Various methods can be used to create large voids or pores in silicon dioxide.

\footnotetext{
* Corresponding author.

E-mail addresses: k_rahmoun@yahoo.fr (K. Rahmoun), alain.iost@ensam.eu (A. Iost), vincent.keryvin@univ-rennes1.fr (V. Keryvin), gildas.guillemot@ensam.eu (G. Guillemot), nechabanesari@yahoo.fr (N.E.C. Sari).
}

An isolation technology for radio frequency applications based on unoxidized porous $\mathrm{Si}$ has been recently reported [4]. This study examines all the important issues relevant to incorporating PS by using Si very-large-scale integration technology, where PS is used as a semi-insulating material. Coplanar wave-guide line measurements showed that the relative dielectric constant of PS films decreases from 9 to 3 with increasing porosity from $24 \%$ to $78 \%$.

The mechanical properties of the porous layers decrease because of porosity, the presence of weak bonds, and the extensive number of traps, voids and mobile ions [5]. However, for device processing and design purposes, information about the mechanical properties is also required. Adequate mechanical properties of this layer are essential for PS films to be used in integrated circuits, because of possible mechanical damage, including film cracking and interface delamination caused by thermal stresses, polishing and other manufacturing processes like wire bonding [6-8]. It is known that, as soon as fabrication starts, PS begins to entrap species from the ambient air. This is the reason why examining the changes in mechanical properties is so important. This is the purpose of this paper. It may be supposed that surface oxidation enhances hardness, improves resistance to film cracking and to interface delamination and therefore eases the integration process of PS films into integrated circuits.

The paper is organised as follows. After presenting the process of PS samples and the conditions for micro-indentation (Section 2), the experimental hardness results are given in Section 3. Section 4 is devoted to the analysis of these results to extract the hardness value of the porous layer, which is usually overestimated by classical approaches. 
Emphasis is then put on a proper multilayer model that is compared with the experimental results.

\section{Experimental procedure}

\subsection{Materials and sample preparation}

Porous silicon layers with a thickness of $5 \mu \mathrm{m}$ and a porosity of $60 \%$ were obtained by anodizing a highly $\mathrm{p}^{+}$-type doped (100) silicon substrate, with 4-6 $\mathrm{m} \Omega \mathrm{cm}$ resistivity, in $\mathrm{HF}$ (50\%): $\mathrm{H}_{2} \mathrm{O}$ : ethanol (2:1:2) solution, at a $50 \mathrm{~mA} \mathrm{~cm}^{-2}$ current density. Anodization was performed at room temperature under dark and galvanostatic conditions. The thickness of the layers was controlled by anodization time. After etching, the samples were cleaned with de-ionized water and dried in air at room temperature.

The samples were stored in ambient air at room temperature in the dark for 1 week, and their morphology was studied using a supra 40 high resolution field emission scanning electron microscope (SEM) on the surface. A cross sectional study was then performed with a JEOL JSM $6301 \mathrm{~F}$ with an operating voltage of $7 \mathrm{kV}$.

Porous silicon is a sponge-like crystalline $\mathrm{Si}$ network containing nanometer-sized Si crystallites. Porosity $p$ was the primary variable of the systematic study and was determined by the gravimetry method using the following equation:

$p=\frac{m_{1}-m_{2}}{m_{1}-m_{3}}$

where $m_{1}$ and $m_{2}$ denote respectively the weight before and after formation of the porous layer. $m_{3}$ is the weight after removal of the porous layer in a $5 \% \mathrm{KOH}$ solution.

The thickness $t$ of the layer is then determined by:

$t=\frac{m_{1}-m_{3}}{S \rho}$

where $\rho$ is the density of the bulk silicon, and $S$ the wafer area exposed to HF during anodization.

The shape of the pores depends on the doping level of the original substrate. High resolution scanning and transmission electron microscopies reveal an anisotropic porous structure referring to a strongly doped $\mathrm{p}^{+}$substrate [9]. This microscopic structure consists of pores oriented perpendicular to the substrate surface and short lateral ramifications. The average diameter of its channels, which propagate throughout the thickness of the layer, is between $3 \mathrm{~nm}$ and $10 \mathrm{~nm}$. For a $60 \%$ porous sample prepared under the same conditions as our sample, the pore size was measured directly from SEM and its distribution was deduced [10]. It ranged from 7 to $30 \mathrm{~nm}$ and was centred on a mean value of $18 \mathrm{~nm}$. From SEM, the size of the wall which separates pores was assessed at about $6 \mathrm{~nm}$ before oxidation.

Fig. 1 shows SEM micrographs of the top surface of the 60\% porosity $\mathrm{p}^{+}$-type porous silicon layer (a) and of the cross section (b). The accurate determination of the pore size distribution in porous $\mathrm{Si}$ is usually given by the analysis of the adsorption isotherms of gases at low temperature $[11,12]$. Unlike non-porous surfaces, the physical adsorption by a porous surface is increased because of capillary condensation inside the pores. This increase in adsorption starts when the gas pressure is high enough to fill in the smallest pores [13]. The method mentioned above also allows an estimate of the developed specific surface of the material, which is very large for porous silicon: $200-1000 \mathrm{~m}^{2} \mathrm{~cm}^{-3}[14]$. Such a large surface contains a huge quantity of impurities coming from the electrolyte used for electrochemical etching and from the ambient air.

The gradual evaporation of the residual electrolyte from the pores causes a very slow increase in oxygen concentration over the first 3 weeks of aging with the following transfer to a linear region as
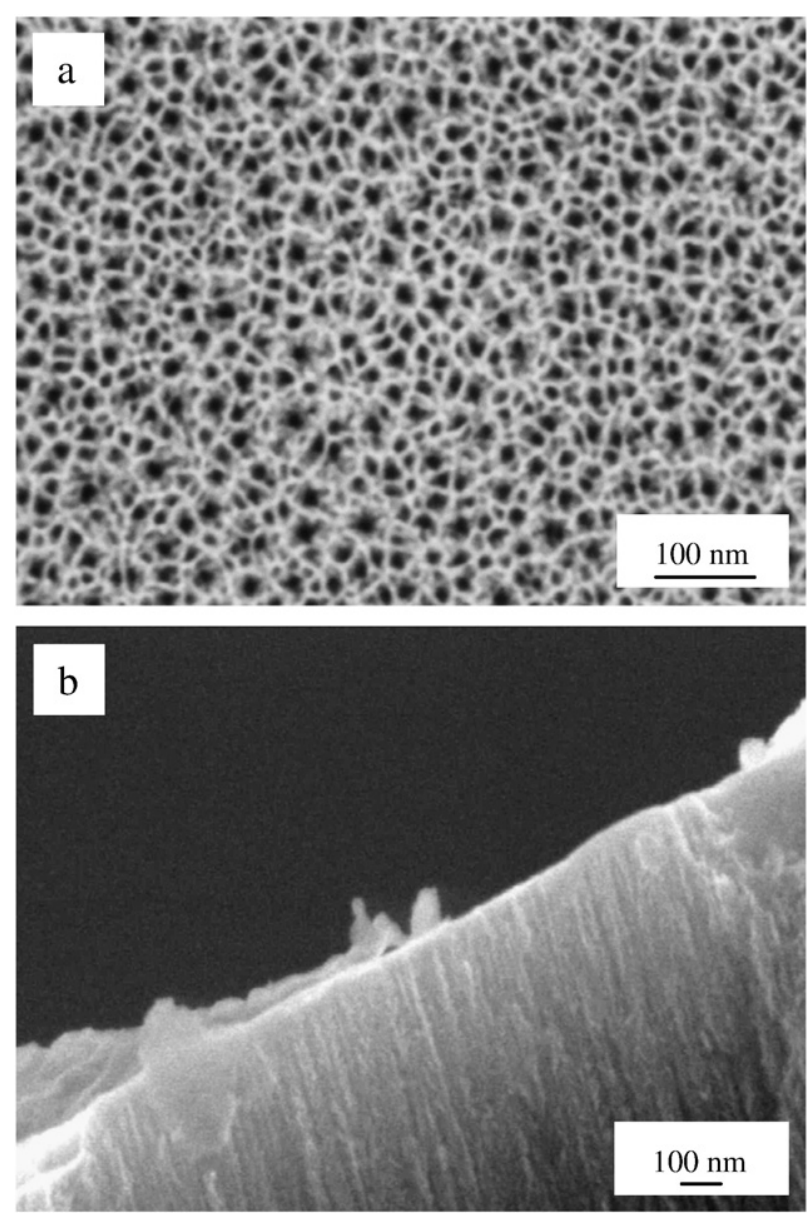

Fig. 1. SEM micrograph of the top surface of the $5 \mu \mathrm{m}$-thick PS film (a) and cross section (b). The porosity was initially about $60 \%$.

reported by E.A. Petrova et al. [15]. They found that the oxidation rate decreased with porosity due to a decrease in the PS inner surface.

For a $60 \%$ porosity and a storage time of 1 week, we deduce that the concentration in oxygen of silicon atoms is approximately $2 \times 10^{21} \mathrm{~cm}^{-3}$.

\subsection{Hardness measurements}

The testing device is a Fischerscope H100 XYp micro-indenter (maximum load of $1 \mathrm{~N}$, load resolution of $0.02 \mathrm{mN}$, depth resolution of $2 \mathrm{~nm}$ ). Indentation consists in continuously applying a load to a specimen with a sharp Vickers pyramid indenter of face angle $136^{\circ}$ and continuously monitoring the penetration depth in the sample. The force is generated electromagnetically and is incrementally increased stepwise up to the peak load of $1,10,100$ or $1000 \mathrm{mN}$. The calibration of the instrument was done by using ISO-14577 procedure and with the help of a reference block. It is done by measuring the difference in hardness calculated with the test force and depth to the constant value of Martens hardness (HM) for the special reference material that shows no depth-dependent values. Note that the constant hardness calibration procedure used here for micro-indentation differs from the constant modulus used in nano-indentation in many respects. Firstly, it does not extract the frame compliance. Secondly, it does not correct the projected area function but the true contact area. As for the frame compliance, Seitzman [16] showed on the same apparatus that it was as low as $4.3 \times 10^{-5} \mathrm{~mm} \mathrm{~N}^{-1}$, so that it can be ignored when indenting soft materials like PS. In our case, the reference material is a BK7 $\otimes$ borosilicate glass. The constant hardness method is performed along two steps. HM is calculated - at every stage of the indentation process - as the ratio of the applied load, $P$ in $\mathrm{N}$, to the resulting true contact area, $A=c h^{2}$ in $\mathrm{mm}^{2}$, 
(without taking into account any piling-up or sinking-in phenomena) calculated starting from the indentation depth:

$H M=\frac{P}{c h^{2}}$

where factor $c$ arises from geometrical considerations of the indenter and is $c=\frac{4 \sin 68^{\circ}}{\cos ^{2} 68^{\circ}}=26.43$ by assuming that the indenter tip is a perfectly sharp Vickers pyramid.

The first correction is based on a non-linear relationship between the experimental measure of depth $h_{\text {raw }}$, and the corrected depth $h_{\text {cor }}$, giving two fitting parameters $k$ and $n$ ensuring a constant value of $H M$ (taking $h_{\text {cor }}$ ) with depth for the reference material:

$h_{\text {cor }}=h_{\text {raw }} \sqrt{1+k h_{\text {raw }}^{n}}$.

This first correction also takes into account the uncertainty of the initial penetration depth (the initial contact force is $0.4 \mathrm{mN}$ ), the thermal drift due to the thermal expansion or contraction of the apparatus (with a temperature sensor in the measuring head) and geometrical imperfections of the tip.

Then a second correction is just a proportionality relationship (here a 0.989 coefficient) between the constant Martens hardness value obtained by the first correction and that of the reference test block standard (here $4134 \mathrm{~N} \mathrm{~mm}^{-2}$ ), so that there is a proportionality relationship between the final value of depth $h$ and the first corrected one $h_{\text {cor }}$. In the following parts, only the last corrected value of the indention depth is considered and is denoted as $h$.

The indentation hardness, HIT (in GPa), is also calculated such that: $H I T=F / A_{c}(h)$, where $A_{c}(h)=24.5 h_{c}^{2}$ is the projected contact area, $h_{c}=h_{\max }-0.75 P_{\max } / S$ is the contact depth, and $S$ is the contact stiffness (unloading curve slope at maximal load $P_{\max }$ : $80 \%$ of this curve were fitted by a power law with the exponent ranging from 1.1 to 1.8 depending on the specimen material) [17].

\section{Results}

For the specimen under consideration, the typical loadingunloading sequence performed under a peak load of $1 \mathrm{~N}$ is shown in Fig. 2.

A more convenient representation, used to interpret the Martens hardness variations, consists in plotting the hardness variations versus the displacement of the indenter tip (see Fig. 3).

The depth profile of hardness shown in Fig. 3 allows us to observe the commonly reported "U shape", typical of low-dielectric-constant

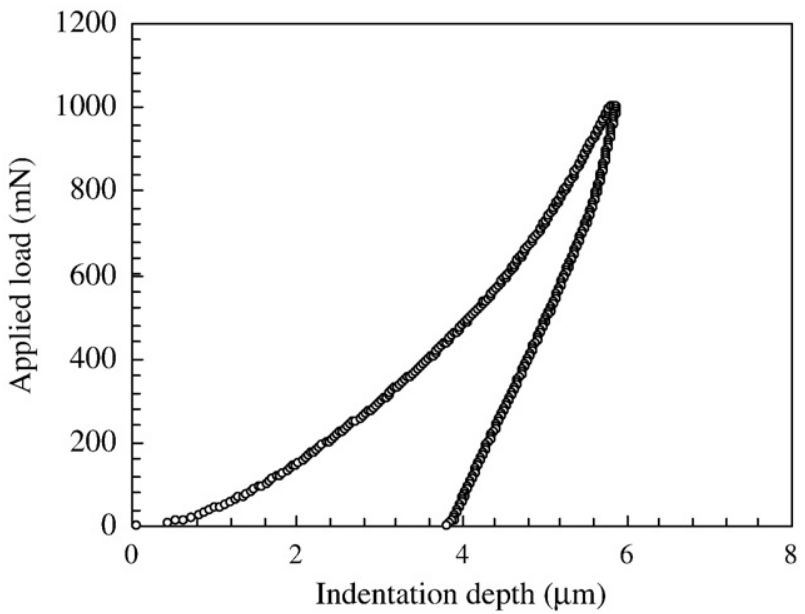

Fig. 2. Typical load versus displacement curve obtained for a one-week aged $5 \mu \mathrm{m}$ porous silicon layer on a Si substrate.

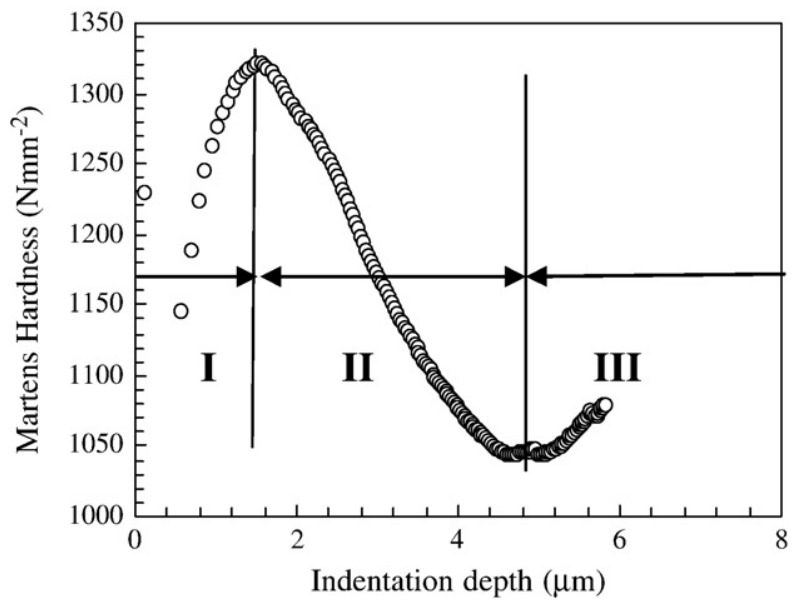

Fig. 3. Variation of Martens hardness versus displacement obtained from Fig. 2

films (regions II/III) as well the existence of three regions with different mechanical properties.

Region I displays abnormal hardness behaviour with increasing hardness as the displacement (and therefore the applied load) increases. Region I is generally associated with a hard and thin cap layer that exists on the top of low- $k$ films [5]. For the specimen under study, this is mainly associated to oxidation and some impurities. Besides it exhibits a Reverse Indentation Size Effect (RISE). The RISE is usually related to the predominance of nucleation, the multiplication of dislocations and the activity of slip mechanisms. All these explanations do not hold for the PS material under study. Our interpretation is related to the indentationinduced cracking phenomenon [18-20] and compaction of the porous structure [21] observed in other materials. Other interpretations are related to the exact determination of the contact area at the very surface layer of the material during the initial stage of indentation [22], or at an experimental artefact due to the pile-up effect $[23,24]$.

Region II corresponds to the main interaction between the surface layer and the soft inner porous silicon layer (the I-layer), while region III corresponds to the main interaction between PS and the hard crystalline Si substrate. Hardness variation with the indentation depth reveals an excursion event as the indenter reaches the substrate (i.e. the indentation depth is $5 \mu \mathrm{m}$ like the coating thickness). Subsequent excursions are also observed respectively at 0.7 and $0.9 \mu \mathrm{m}$ of increased penetration, as shown in Fig. 4 (a magnification of Fig. 3). These

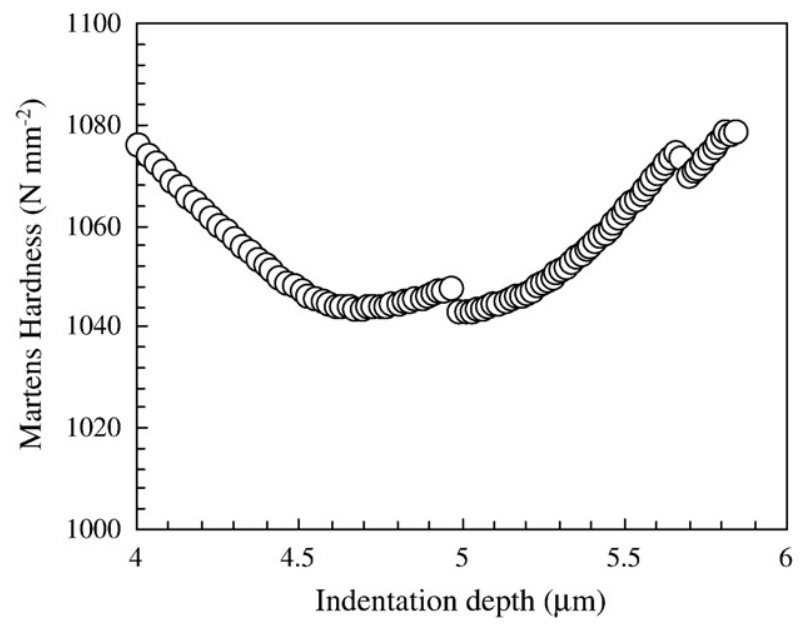

Fig. 4. Excursion event in hardness variations as the indenter reaches the Si. 
excursions are related to pop-ins observed on the load-displacement curves.

Pop-in events are also observed at a smaller scale when performing the hardness test at a $10 \mathrm{mN}$ peak load (Fig. 5). This figure also shows that the test is reproducible in the loading part of the indentation process used to calculate the Martens hardness. These pop-ins are expected to operate through the bursting of dislocations in Si substrate [25], the breaking of the top layer (as in carbon-doped low- $k$ materials) [5], crack initiation around the pores, connection to each other and continuous propagation along the pores (as in porous $\mathrm{SiO}_{2}$ ) [7], phase transformation in the silicon substrate $[26,27]$ or the crumbling of the PS cellular structure [27].

It is often assumed that the minimum in hardness or elastic modulus (or the plateau region when it exists) (see Fig. 3) indicates the best estimate of the coating's mechanical properties [28-35]. Whether or not the minimum in hardness estimates the mechanical properties of the coating was addressed by Vella et al. [35], because some film effects may overlap with the substrate effects thereby increasing the minimum point. Some doubts were also raised by Vitiello et al. [36] who showed by studying ultra porous low- $k$ multilayers that minima are affected by the number of layers (and then the coating thickness) and may overestimate the real value.

For these reasons, the main objective of this paper is to propose a model that can describe the true hardness of the soft porous inner layer. The starting point is the hardness area law of mixture by Jönsson and Hogmark [37], which requires the determination of the substrate properties.

\section{Discussion}

\subsection{Determination of the Si substrate hardness}

Indentation tests on the $\mathrm{Si}$ (100) substrate were performed at 10,100 and $1000 \mathrm{mN}$ peak loads (the figures are not represented in this paper). Pop-in and pop-out events were clearly observed respectively during the loading and the unloading stages. They are related to the occurrence of dislocation propagations, cracks and crystallographic modifications [25]. For loads lower than $100 \mathrm{mN}$, the Martens hardness is nearly constant: $H M_{S i} \approx 6600 \mathrm{Nmm}^{-2}$, whereas HIT data are about two or three times higher depending on the applied load. These results fit in well with Bouzakis et al.'s data [38] who found a constant Martens hardness of $7070 \mathrm{Nmm}^{-2}$ and a variation of HIT between 14 and $20 \mathrm{GPa}$

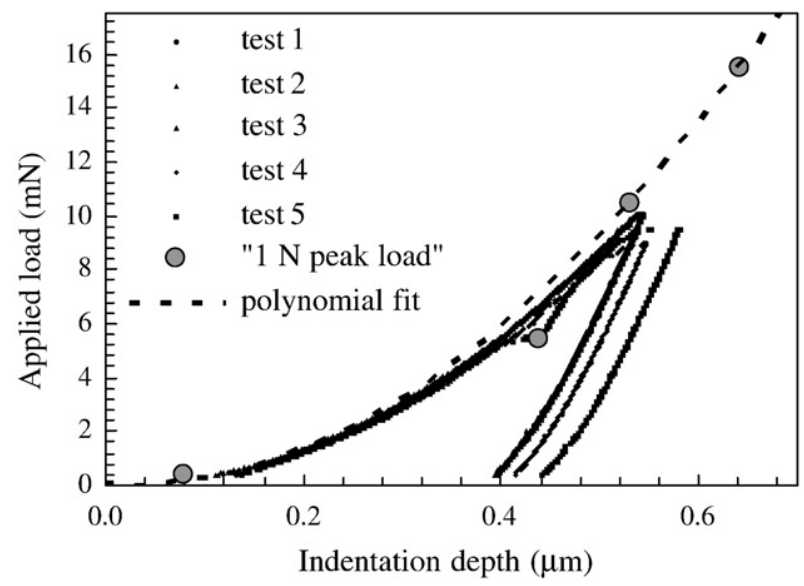

Fig. 5. Loading-unloading curves showing pop-ins in the experimental data for low load measurement, and the first data corresponding to the $1 \mathrm{~N}$ peak load curve represented in Fig. 2.

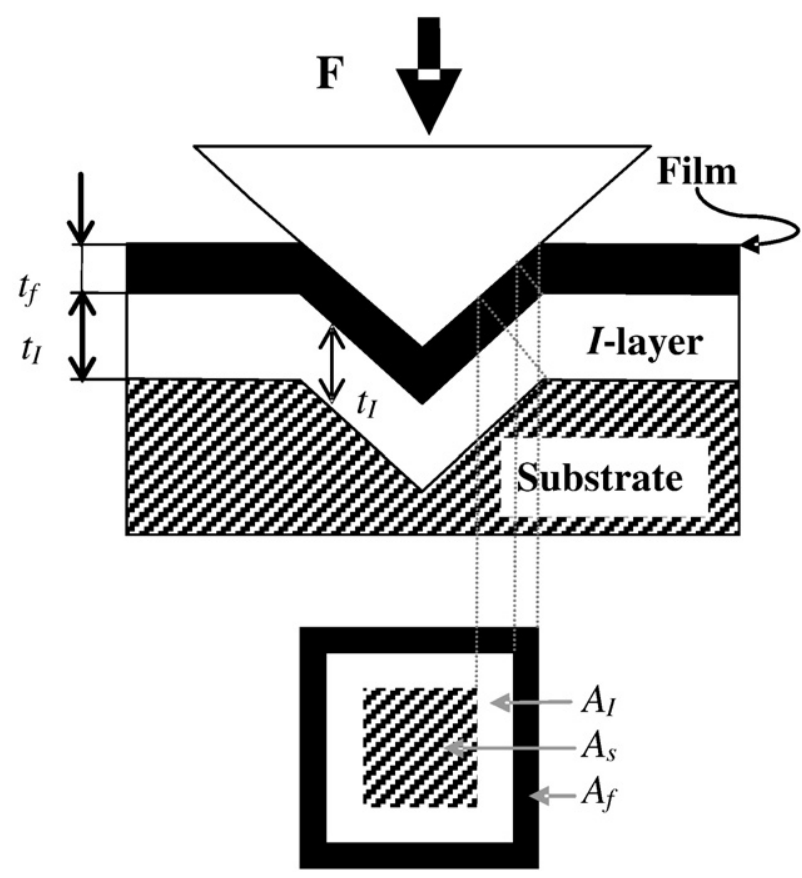

Fig. 6. Schematic representation of the hardness area law of mixture for a plastically deformed film.

(for applied load of respectively 20 and $3 \mathrm{mN}$ ) for Si (100). Such a difference between HM and HIT (or the conventional Vickers Hardness Number) is also quoted by Jang [39] for $\mathrm{Y}_{2} \mathrm{O}_{3}-\mathrm{ZrO}_{2}$ ceramics, by Ullner et al. [40] for silicon nitride or aluminium oxides and by Fischer Cripps et al. [41] for sapphire standard blocks. Consequently, a constant Martens hardness of $6600 \mathrm{Nmm}^{-2}$ is considered in the following model for the Si substrate.

\subsection{The JH Hardness area law of mixture}

The well-known Jönsson and Hogmark model (JH model) [37] based on an area law of mixture is widely used to calculate the film hardness when the indenter penetration is influenced by the substrate, i.e. the indentation depth is superior to about $10 \%$ of the film thickness $t[42,43]$.

Let $h=h_{f}+h_{s}$ be the total indentation depth, $A_{f}$ and $A_{s}$ respectively the coating and substrate area transmitting the mean contact pressure $H_{f}$ and $H_{s}$, and $A=A_{f}+A_{s}$ the total indented area (see Fig. 6 with $\left.t_{I}=0\right)$. Since the indented area is proportional to the square of the indentation depth for a self-similar sharp indenter then:

$$
\begin{aligned}
& A_{f}=c h^{2}-c\left(h-h_{f}\right)^{2} \\
& \frac{A_{f}}{A}=\frac{2 h_{f}}{h}-\frac{h_{f}^{2}}{h^{2}}
\end{aligned}
$$

or

$$
\frac{A_{f}}{A}=\frac{2 C t_{f}}{h}-\frac{C^{2} t_{f}^{2}}{h^{2}}
$$

The geometrical constant, $C$, expressed in relation with the apical semi angle $\varphi$ is equal to $\cos ^{2} \varphi$ for a plastically deformed film and to $(1-\sin \varphi)$ if cracks develop in the film. The values of angle $\varphi$ are represented in Table 1 for the indenters generally used in nano or micro-indentation. 
Table 1

Values of the angle $\varphi$ and of the relative constant $C$ for Vickers, Berkovich, conical and cube corner indenters.

\begin{tabular}{lllll}
\hline Indenter tip & Vickers & Berkovich & Conical $\left(120^{\circ}\right)$ & Cube corner \\
\hline$\varphi\left(^{\circ}\right)$ & 68 & 65.3 & 60 & 35.26 \\
$C_{1}$ & 0.1403 & 0.1746 & 0.25 & 0.6667 \\
$C_{2}$ & 0.0728 & 0.0915 & 0.1340 & 0.4227 \\
$C_{1}^{\prime}$ & $1-0.8597 \beta$ & $1-0.8254 \beta$ & $1-0.75 \beta$ & $1-0.3333 \beta$ \\
$C_{2}^{\prime}$ & $1-0.9272 \beta$ & $1-0.9085 \beta$ & $1-0.8660 \beta$ & $1-0.5773 \beta$
\end{tabular}

The subscripts 1 and 2 referred respectively to a plastically deformed film and a cracked film.

Then the composite hardness $H_{c}$ that represents both the contribution of the coating and the substrate, is given by the area law of mixture:

$H_{c}=\frac{A_{f}}{A} H_{f}+\frac{A_{s}}{A} H_{s}$

Combining Eq. (8) with Eq. (7) gives:

$\left.\left.H_{c}=2 \frac{C t_{f}}{h}-\frac{C^{2} t_{f}^{2}}{h^{2}}\right) H_{f}+1-2 \frac{C t_{f}}{h}+\frac{C^{2} t_{f}^{2}}{h^{2}}\right) H_{s}$

or:

$\left.\frac{H_{c}-H_{s}}{H_{f}-H_{s}}=a=2 \frac{C t_{f}}{h}-\frac{C^{2} t_{f}^{2}}{h^{2}}\right)$

where the substrate and the film hardness values may vary according to the applied load [44-46] such that:

$H_{i}=H_{0 i}+\frac{B_{i}}{h}$

where $i$ may refer to the substrate $(i=s)$ or the film $(i=f)$. It is sometimes reported that the fit given by Eqs. (9) and (10) does not pass through the data points [47-49]. The breakdown observed in fitting the experimental results by the $\mathrm{JH}$ model at high and low indention depths is generally attributed to the polynomial form that is advocated for Eqs. (9). However this criticism makes no allowance for the physical significance of the model for which $A_{f} / A$ and $A_{s} / A$ must lie between 0 and 1 [50]. For example, if the indentation depth is lower than the seventh of the coating thickness, then $A_{f}=A ; A_{s}=0$ and therefore $H_{c}=H_{f}$. Buckle's rule consisting in limiting the indentation depth to less than $10 \%$ of the film thickness is extended to nearly $15 \%$ by using the $\mathrm{JH}$ model. It should be noticed that the $10 \%$ rule is often found to be too conservative [51] particularly in the case of soft coatings deposited on harder substrates $[23,52]$. In the following part, we show that the $15 \%$ rule is also too conservative for the material under study.

\subsection{Generalisation of the hardness law of mixture}

The generalisation of the hardness area law of mixture to multilayers by Engel $[53,54]$ presents the same limitations as the original Jönsson and Hogmark model; therefore we propose the following formalism taking into account the physical meaning related to the indented area.

Considering that the area $A_{I}$ of the I-layer supports the indenter, then from Fig. 6:

$\frac{A_{I}}{A}=\frac{2 h_{I}}{h}-\frac{h_{I}^{2}}{h^{2}}-2 \frac{h_{I} h_{f}}{h^{2}}$ or:

$\frac{A_{I}}{A}=\frac{2 C_{I} t_{I}}{h}-\frac{C_{I}^{2} t_{I}^{2}}{h^{2}}-2 \frac{C_{I} t_{I} C_{f} t_{f}}{h^{2}}$

where $t_{I}$ is the depth of the $I$-layer, and $C_{I}, C_{f}$ may have the value $\cos ^{2} \varphi$ or $(1-\sin \varphi)$ depending on the layer's propensity to undergo plastic deformation. Then the composite hardness is:

$H_{c}=\frac{A_{f}}{A} H_{f}+\frac{A_{I}}{A} H_{I}+\frac{A_{s}}{A} H_{s}$.

As for the two-layer model, it must be pointed out that all ratios $A_{f} / A$, $A_{\mathrm{I}} / A, A_{s} / A$ must lie between 0 and 1 , and $A_{f}+A_{I}+A_{s}=A$. As a consequence, if $h_{f}+h_{I}=h$, (i.e. $\left.C_{f} t_{f}+C_{I} t_{I}=h\right)$ then $\frac{A_{I}}{A}+\frac{A_{f}}{A}=1$, and $A_{s}=0$, therefore:

if $h \leq C_{f} t_{f}+C_{I} t_{I}$, then $\frac{A_{I}}{A}=1-\frac{A_{f}}{A}$

where $A_{f} / A$ is given by Eq. (7). This model can easily be generalized to $N$ layers. Fig. 7 shows the hardness variation versus the reciprocal indentation depth for experimental data shown in Fig. 2.

This representation is used to test whether the model (Eqs. (11)-(14)) can account for the experimental results. It thus makes it possible to calculate the surface layer hardness by using the linear part for the lower loads applied. The linear regression gives: $H_{f}=1447-178 / \mathrm{h} \mathrm{N} \mathrm{mm}^{-2}$. The deviation from linearity arises at about $1 / h=0.7 \mu \mathrm{m}^{-1}$ (i.e. $h=1.4 \mu \mathrm{m}$ ). From the JH model in Eq. (6), at this deviation $C t=h$ and then the surface layer thickness is about $10 \mu \mathrm{m}$ in case of a plastically deformed film, and $20 \mu \mathrm{m}$ in case of a cracked film. This result is obviously wrong since the total thickness of the porous layer is only $5 \mu \mathrm{m}$. Such behaviour was already observed by Iost et al. for paint-coatings deposited on metallic substrates [55].

\subsection{Multilayer model with crumbling assumption}

The discrepancy observed between the experimental data and modelling is expected because of cracking, plasticity and the local densification underneath the indenter of the highly porous silicon layer as observed by Bellet et al. for example [27]. Therefore, the

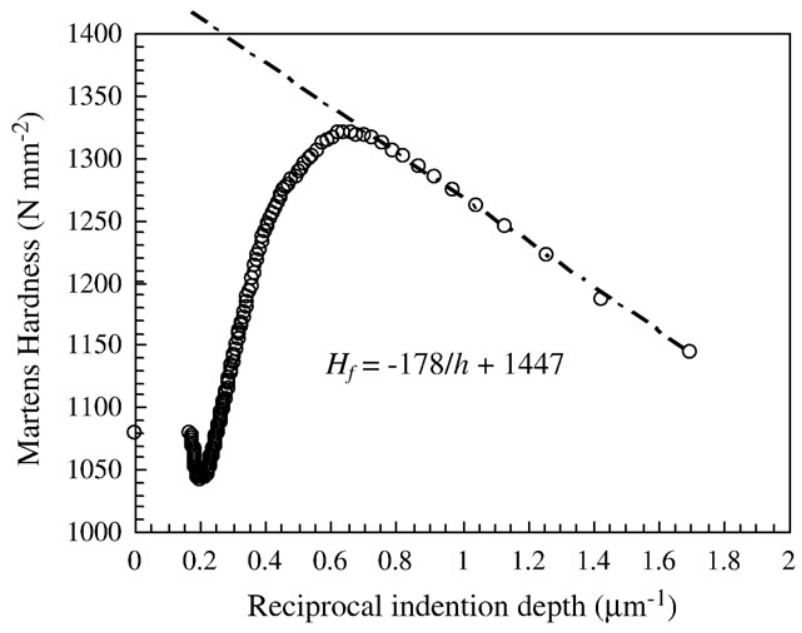

Fig. 7. Variation of Martens hardness with the reciprocal indentation depth. The straight line corresponds to the top layer hardness variation with the applied load (then with the indentation depth). 
above-mentioned model has to be improved to account for these effects.

The crumbling effect under the stress field imposed by the indentation load is represented in Fig. 8, in which the thickness, $t_{i}$, of the $i$-layer $(i=f$ or $I)$ is reduced to $t_{i}^{\prime}=\beta_{i} t_{i}$, with $0 \leq \beta_{i} \leq 1$.

Then, from simple geometrical considerations, constant $C$ in Eq. (12) becomes $C^{\prime}$ such that:

$C_{1}^{\prime}=1-\beta \sin ^{2} \varphi$, or $C_{2}^{\prime}=1-\beta \sin \varphi$

respectively in the case of a plastically deformed or cracked film. For a Vickers pyramidal indenter, these constants become respectively $C_{1}^{\prime}=1-$ $0.8597 \beta$ and $C_{2}^{\prime}=0.9272 \beta$. The values of $C^{\prime}$ for other indenters are shown in Table 1.

All Eqs. (5)-(14) in Sections 4.2 and 4.3 are valid when considering the reduction of thickness of the cap $(i=f)$ or inner $(i=I)$ layers, provided $\beta_{i} t_{i}$ is used in place of $t_{i}$, or $C_{i}^{\prime} t_{i}$ in place of $C_{i} t_{i}$.

Fig. 9 presents the experimental data and the model obtained with the aforementioned values for the substrate: $H_{s}=6600 \mathrm{Nmm}^{-2}$, the film $H_{f}=1447-178 / h \mathrm{~N} \mathrm{~mm}^{-2}$, and $C_{f}^{\prime} t_{f}=1.327 \mu \mathrm{m}$ (from Fig. 7). The best fit obtained by minimizing the difference between the theoretical curve and the experimental data, by a least-mean squares method, gives $C_{I}^{\prime} t_{I}=3.692 \mu \mathrm{m}$ and $H_{I}=704.5 \mathrm{Nmm}^{-2}$. It must be emphasized that only the product $C_{I}^{\prime} t_{I}$ is known; it is impossible to calculate either the layer thickness or the compaction factor $\beta_{I}$ via this model. The hardness of the porous silicon $\left(704.5 \mathrm{Nmm}^{-2}\right)$, differs drastically from the minimum in the hardness plot observed in Fig. $3\left(1049 \mathrm{Nmm}^{-2}\right)$. Contrary to what is usually reported in literature [28-35], the minimum in hardness value does not correspond to the real hardness of the coating, but it is generally an over-estimated value as assumed by Vitiello et al. [36].

Having thorough knowledge of the three layers' hardness, our model aims to calculate the minimum in the hardness curve and its location with relation to thicknesses of the different layers. From

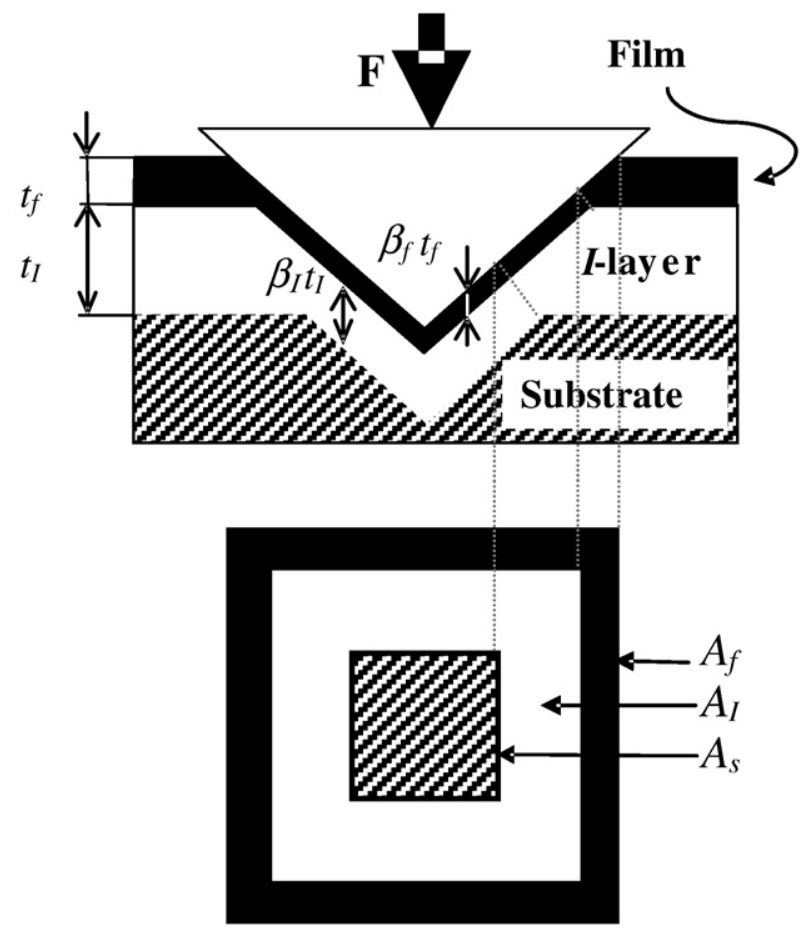

Fig. 8. Schematic representation of the hardness area law of mixture for a plastically deformed film accounting for the crushing of the porous layer.

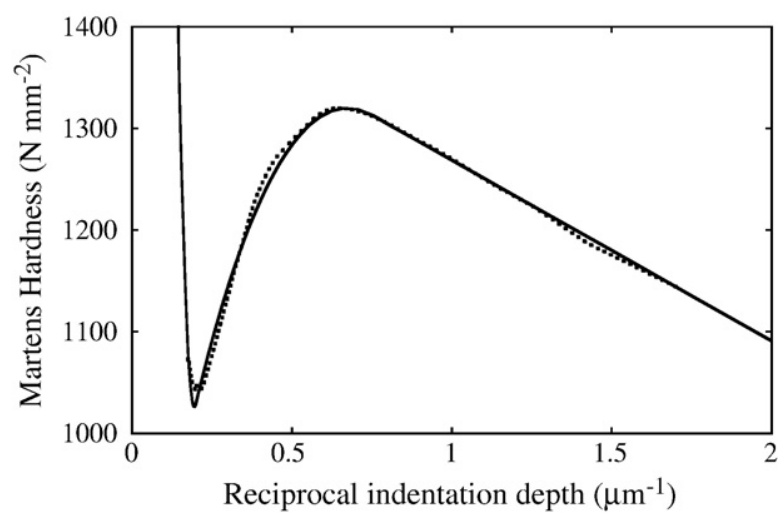

Fig. 9. Comparison between experimental hardness data (solid curve) and the model modified to account for the crumbling effect (dotted line). The input values are: $H_{s}=6600 \mathrm{~N} \mathrm{~mm}^{-2} ; H_{f}=1447-178 / h \mathrm{~N} \mathrm{~mm}^{-2} ; C_{f}^{\prime} t_{f}=1.327 \mu \mathrm{m}$. The regression is performed such that $H_{I}$ and $C_{I}^{\prime} t_{I}$ minimized the difference between the model and the experimental data.

Eqs. (11)-(15), and considering a constant hardness value for the film, this minimum is:

$\frac{1}{h}=\frac{1+\gamma}{C_{I}^{\prime} t_{I}+C_{f}^{\prime} t_{f}}$

where

$\gamma=\frac{\lambda\left(H_{I}-H_{f}\right)}{\left(H_{s}-H_{I}\right)(1+2 \lambda)+\lambda^{2}\left(H_{s}-H_{f}\right)}$

and

$\lambda=\frac{C_{f}^{\prime} t_{f}}{C_{I}^{\prime} t_{I}}$

The minimum depends on the hardness of the three phases, the thickness of the two coatings and the crumbling effect. The minimum is reached if $-1<\gamma<0$ such that:

$H_{c}^{\min }=H_{f}-\frac{\left(H_{f}-H_{I}\right)\left(H_{I}-H_{s}\right)}{\left(H_{I}-H_{s}\right)(1+2 \lambda)+\lambda^{2}\left(H_{f}-H_{s}\right)}$.

The minimum is not reached if $\gamma \geq 0$, and has no physical meaning $(h<0)$ if $\gamma \leq-1$. With the values obtained in Fig. 9, the minimum in

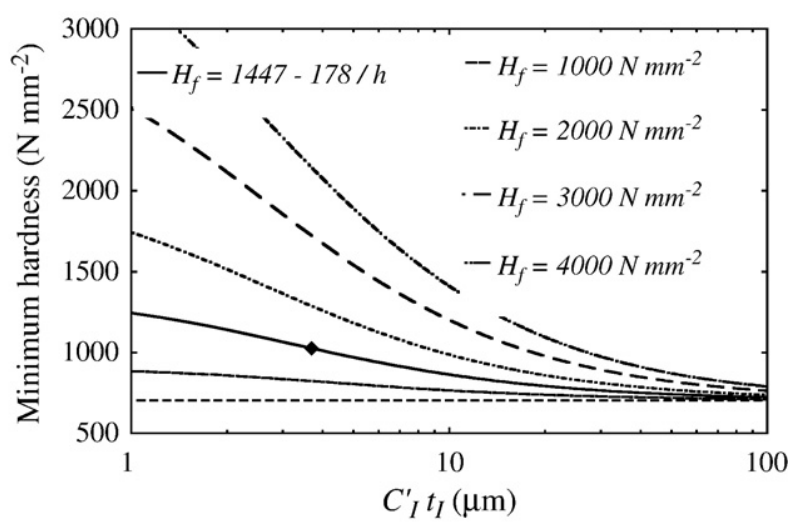

Fig. 10. Variation of the minimal hardness of the "U shape "curve with the thickness of the PS inner layer. The solid curve is related to our specimen and the square data point corresponds to $C_{I} t_{I}=3.7 \mu \mathrm{m}$, the dotted curves correspond to cap layers with different hardnesses, and the dotted horizontal line represents the true hardness of the innerlayer $H_{I}=704.5 \mathrm{Nmm}^{-2}$ found from the regression analysis performed in Fig. 9. 
hardness corresponding to Eq. (19) can be plotted versus the I-layer's thickness. The curve in solid line (Fig. 10) shows the evolution of the minimum in hardness with the $C_{I}^{\prime} t_{I}$ parameter if $H_{s}$ and $H_{f}$ have the values previously used in Fig. 9. If $H_{f}$ is considered now as a function of the indentation depth $h$ (ISE effect), the minimal value $H_{c}^{\min }$ is not expressed by Eqs. (16) and (19). It has been calculated using Mathematica $($. We show that this minimum in hardness is highly dependent on the thickness of the layer. It must also be noticed that $H_{\text {min }}$ tends to the true hardness of the I-layer as the product $C_{I}^{\prime} t_{I}$ increases. Fig. 10 also shows (dotted lines) that for a given I-layer thickness, the minimum in hardness observed in the U-shaped curve is highly dependent on the mechanical properties of the cap layer. The harder the film, the higher the difference between the minimum and the true hardness for the I-layer. Some authors $[5,28,29]$ have recently claimed that the cube corner tip is more appropriate than that of Berkovich (or Vickers) to determine the hardness of the coating. This observation is in agreement with the data reported in Table 1 for various indenter shapes: as coefficient $C^{\prime}$ is higher for the cube-corner tip than for the Vickers (or Berkovich), the substrate effect starts at much deeper indentation depths. However, for the specimen under study, the minimum in hardness is also affected by the top layer. Taking the same $C^{\prime}$ value for the film and the I-layer in Eqs. (17) and (19), $\lambda$ is constant and the minimum in hardness is independent of the indenter's geometry. From Eq. (19), as $C^{\prime}$ rises, the minimum in hardness is shifted towards the low values of $1 / h$ (i.e. the highest values of the applied load). This result is consistent with previous experimental observations $[5,29,30]$. The minimum in the $U$ curve may change if the cube corner indenter modifies the behaviour of the cap layer, for example, by promoting the crack formation as a consequence of the more intense stress field.

This result is consistent with the observations by Vitiello et al. [36] and may explain Wang et al.'s results, for example [8]. The authors observed that the Young modulus and the hardness of polytetrafluoroethylene films strongly depend on the film's thickness. These mechanical properties decrease when increasing the film's thickness and become independent when films are thick enough as observed in Fig. 10.

Regarding the calculated values which allow to obtain the best fit in Fig. 9, it can be observed that $C_{f}^{\prime} t_{f}+C_{I}^{\prime} t_{I}=5.02 \mu \mathrm{m}$, corresponds to the expected total thickness of the coating $t_{f}+t_{I}(5 \mu \mathrm{m})$. As a consequence, $C_{f}^{\prime}=C_{I}^{\prime}=1$ and therefore $\beta_{f}=\beta_{I}=0$. This fact is confirmed in Fig. 11, which shows the variation of the ratios of the area which supports the indenter pressure $A_{f} / A, A_{I} / A$ and $A_{s} / A$ (coefficients in Eq. (13) calculated for the best fit in Fig. 9) versus the indentation depth. It is shown that if the indenter depth is lower than the $5 \mu \mathrm{m}$ coating thickness, then $A_{s} / A=0$. Consequently the hardness that is measured

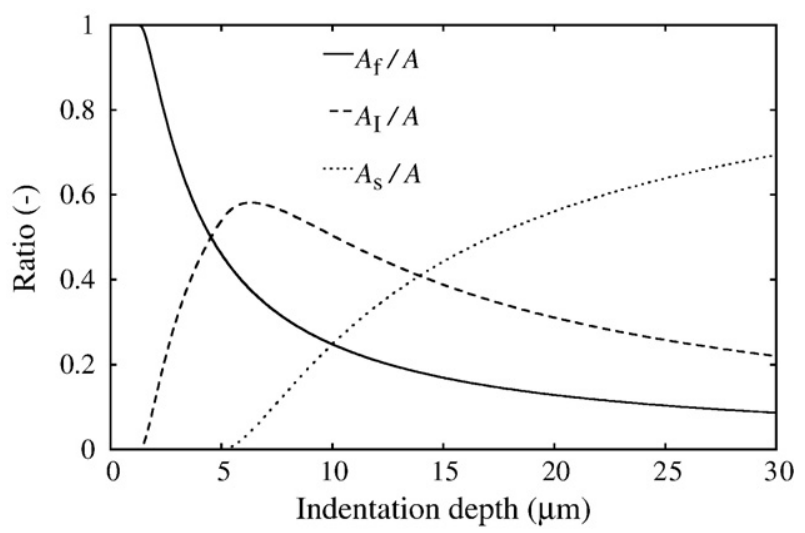

Fig. 11. Variation of $A_{f} / A, A_{I} / A$ and $A_{S} / A$ versus the indenter penetration depth for the three-layer composite model and the experimental results.

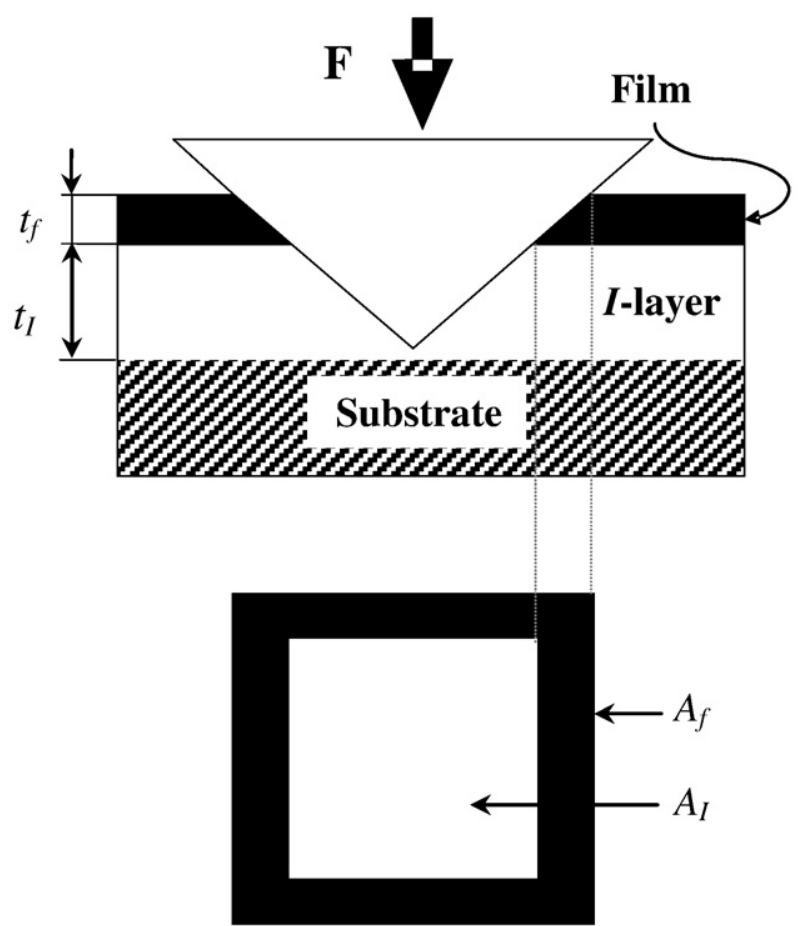

Fig. 12. The simplified model Eq. (20) with $\beta_{f}=\beta_{I}=0$.

only depends on the cap-layer $\left(A_{f} / A=0.45\right)$ and on the inner-layer $\left(A_{I} /\right.$ $A=0.55)$ until the indenter reaches the substrate.

The model mentioned above has been simplified since the coating is punched by the indenter as represented in Fig. 12, such that:

$$
\begin{aligned}
& H_{c}=\frac{A_{f}}{A} H_{f}+\frac{A_{I}}{A} H_{I}+\frac{A_{s}}{A} H_{s} \\
& \frac{A_{f}}{A}=\frac{2 t_{f}}{h}-\frac{t_{f}^{2}}{h^{2}} \\
& \frac{A_{I}}{A}=\frac{2 t_{I}}{h}-\frac{t_{I}^{2}}{h^{2}}-2 \frac{t_{I} t_{f}}{h^{2}} \\
& \frac{A_{s}}{A}=1-\frac{2\left(t_{f}+t_{I}\right)}{h}+\frac{\left(t_{f}+t_{I}\right)^{2}}{h^{2}}
\end{aligned}
$$

From this model (which has some features in common with the Kao and Byrne approach [56]) it can be shown that the substrate begins to influence the coating hardness at the critical penetration depth $h=t_{f}+t_{\mathrm{r}}$. The SEM observation of the fracture path obtained by breaking a sample along the cracks created at a corner of a Vickers indentation performed under a $50 \mathrm{~N}$ load (Fig. 13) shows that the indenter passes through the top and inner layers, and that the latter is nearly $4 \mu \mathrm{m}$ thick. This value is in accordance with $C_{I}^{\prime} t_{I}=3.692 \mu \mathrm{m}$ found during the regression performed to obtain Fig. 9.

From the results presented above, we can deduce that the substrate does not influence the hardness for indentation depths lower than the coating thickness. As a consequence, a model with only two layers, the oxidized surface and the porous silicon layer, may be used to calculate the I-layer hardness by multi regression analysis. Fig. 14 represents the experimental hardness variation with the reciprocal indentation depth. Taking $H_{f}=1447-178 / h \mathrm{~N} \mathrm{~mm}^{-2}$ for the film hardness as determined above, the best fit is obtained with $H_{I}=700 \mathrm{~N} \mathrm{~mm}^{-2}$ (the I-layer is considered here as the substrate). This result fits in well with the values obtained above. 

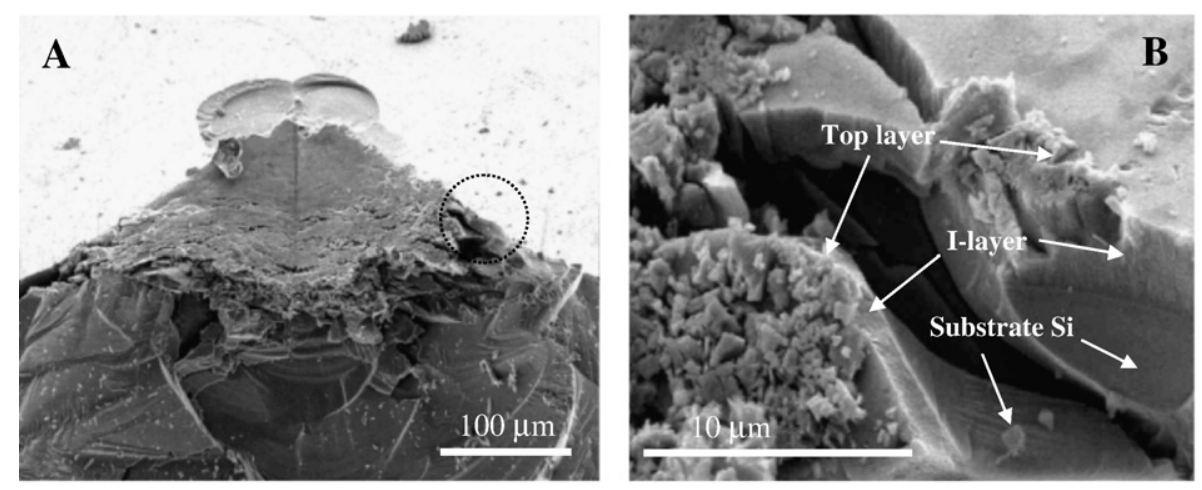

Fig. 13. SEM observation of the deformed zone near the indentation print. (A): general view; (B): enlargement of the area in the circle indicated in view (A).

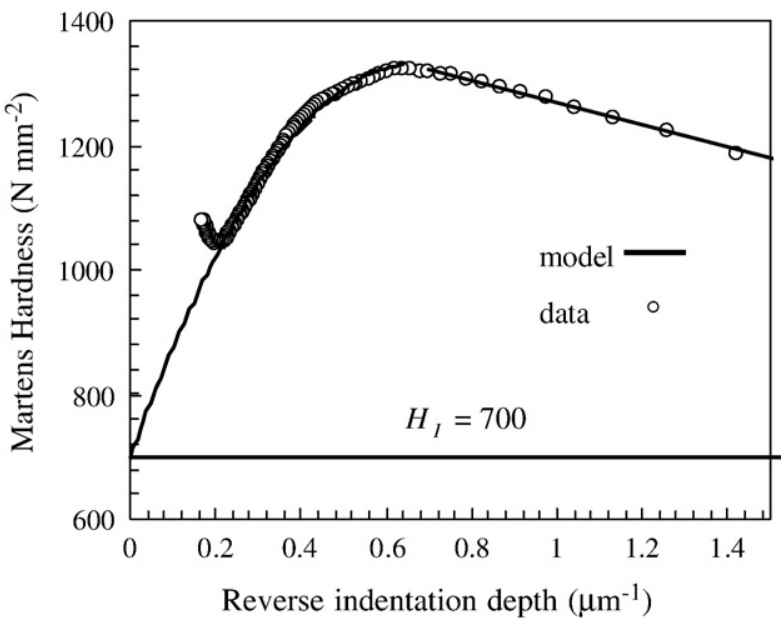

Fig. 14. Experimental results and two-layer modelling. The open circles correspond to the experimental data, the upper curve to the simplified model (a hard top layer on a softer inner-layer without interaction with the silicon substrate) and the lower straight line to the inner-layer hardness obtained by regression.

\section{Summary and conclusions}

In this paper we have studied the Martens hardness of a one-week aged porous silicon layer with a $5 \mu \mathrm{m}$ thickness and 60\% porosity obtained by anodization of a highly $\mathrm{p}^{+}$-type doped (100) silicon substrate. To take into account the hardness variation to the applied load and the crumbling of the porous coating, a multilayer model is proposed. This model, based on the Jönsson and Hogmark's area law of mixtures, makes it possible to calculate the minimum in hardness value which depends on the hardness of the different phases, the thickness of the coatings and the compaction of the layers under the load transmitted by the Vickers indenter. This minimum is generally an over-estimated value of the real hardness of the inner layer and this result has to be considered when studying the hardness of low-dielectric-constant films. It must be emphasized that hardness (elastoplastic behaviour) is less dependent on the substrate's hardness than Young's modulus is, because elastic fields have longer ranges than plastic fields, which are a localized. Therefore the determination of the Young's modulus of low- $k$ materials raises more difficulty than that of the hardness.

\section{Acknowledgements}

One of the authors (K.R.) wants to thank Pr. Lazhar Haji for her proposal of a research stay at Laboratoire d'Optronique, CNRS-UMR FOTON 6082, Université de Rennes 1, France. The authors also wish to thank Dr. M. Gendouz (Laboratoire d'Optronique, CNRS-UMR FOTON
6082, Université de Rennes 1), J. Le Lannic (CMEBA, Université de Rennes 1), Pr. C. Mathieu (CCML Université d'Artois, Faculté Jean Perrin de Lens, France), and V. Hague (ENSAM Lille, France) respectively for their help with sample preparation, HR SEM or SEM observations and assistance as regards English.

\section{References}

[1] A. Uhlir, Bell Syst. Tech. J. 35 (1956) 333.

[2] D.R. Turner, J. Electrochem. Soc. 105 (1958) 402.

[3] L.T. Canham, Appl. Phys. Lett. 57 (1990) 1046.

[4] H.-S. Kim, Y.-H. Xie, M. De Vincentis, T. Itoh, K.A. Jenkins, J. Appl. Phys. 93 (2003) 4226

[5] M. Fujikane, S. Nagao, X.W. Liu, D. Chrobak, A. Lehto, S. Yamanaka, R. Nowak, J. Alloys Compd. 48 (2008) 293.

[6] S.-Y. Chang, Y.-C. Huang, Microelectron. Eng. 84 (2007) 319.

[7] S.-Y. Chang, Y.-C. Huang, Microelectron. Eng. 83 (2006) 1940.

[8] J. Wang, F.G. Shi, T.G. Nieh, B. Zhao, M.R. Brongo, S. Qu, T. Rosenmayer, Scr. Mater. 42 (2000) 687.

[9] A.G. Cullis, L.T. Canham, Nature 353 (1991) 335.

[10] P. Pirasteh, J. Charrier, A. Soltani, S. Haesaert, L. Haji, C. Godon, N. Errien, Appl. Surf. Sci. 253 (2006) 1999.

[11] S. Brunauer, P.H. Emmet, E. Teller, J. Am. Chem. Soc. 60 (1938) 309.

[12] G. Bomchil, R. Herino, K. Barla, J.C. Pfister, J. Electrochem. Soc. 130 (1983) 1611.

[13] O. Bisi, S. Ossicini, L. Pavesi, Surf. Sci. Rep. 38 (2000) 1.

[14] S. Billat, PhD Thesis, Université de Grenoble 1, France, 1994.

[15] E.A. Petrova, K.N. Bogoslovskaya, L.A. Balagurov, G.I. Kochoradze, Mater. Sci. Eng., B 69/70 (2000) 152.

[16] L.E. Seitzman, J. Mater. Res. 13 (1998) 2936.

[17] W.C. Oliver, G.M. Pharr, J. Mater. Res. 19 (2004) 3.

[18] H. Li, R.C. Bradt, J. Mater. Sci. 31 (1996) 1065-1070.

[19] J. Gong, H. Miao, Z. Zhao, Z. Guan, Mater. Sci. Eng., A 303 (2001) 179.

[20] P. Feltham, R. Banerjee, J. Mater. Sci. 27 (1992) 1626.

[21] V.M. Anandakumar, A. Khadar, Cryst. Res. Technol. 43 (2008) 193.

[22] R. Nowak, C.L. Li, M.V. Swain, Mater. Sci. Eng., A 253 (1998) 67.

[23] R. Saha, W.D. Nix, Acta Mater. 50 (2002) 23.

[24] L. Hu, X. Zhang, Y. Sun, R.J.J. Williams, J. Sol-Gel Sci. Technol. 34 (2005) 41.

[25] O. Bernard, A.M. Huntz, M. Andrieux, W. Seiler, V. Ji, S. Poinsonnet, Appl. Surf. Sci. 253 (2007) 4626

[26] Y.-H. Lin, T.-C. Chen, P.F. Yang, S.-R. Jian, Y.-S. Lai, Appl. Surf. Sci. 254 (2007) 1415

[27] D. Bellet, P. Lamagnère, A. Vincent, Y. Bréchet, J. Appl. Phys. 80 (1996) 3772.

[28] L. Shen, K. Zeng, Microelectron. Eng. 71 (2004) 221.

[29] M. Johnson, Z. Li, J. Wang, Y. Yan, Thin Solid Films 515 (2007) 3164.

[30] R.J. Nay, O.L. Warren, D. Wang, T.J. Wyrobek, Microelectron. Eng. 75 (2004) 103.

[31] K. Zeng, Z-K. Chen, L. Shen, B. Liu, Thin Solid Films 477 (2005) 111.

[32] K.H. Lee, J.-H. Yim, M.R. Baklanov, Microporous Mesopororous Mater. 94 (2006) 113.

[33] S. Yu, T.K.S. Wong, X. Hu, M.S. Yong, J. Sol-Gel Sci. Technol. 35 (2005) 69

[34] S. Yu, T.K.S. Wong, X. Hu, J. Wei, M.S. Yong, Microelecton. Eng. 77 (2005) 125.

[35] J.B. Vella, I.S. Adhihetty, K. Junker, A.A. Volinsky, Int. J. Fract. 119/120 (2003) 487.

[36] J. Vitiello, A. Fuchsmann, L.-L. Chapelon, V. Arnal, D. Barbier, J. Torres, Microelectron. Eng. 82 (2005) 422.

[37] B. Jönsson, S. Hogmark, Thin Solid Films 114 (1984) 257.

[38] K.D. Bouzakis, N. Michailidis, Thin Solid Films 494 (2006) 155.

[39] B.K. Jang, J. Alloys Compd. 426 (2006) 312.

[40] C. Ullner, J. Beckmann, R. Morrell, J. Eur. Ceram. Soc. 22 (2002) 1183.

[41] A.C. Fischer-Cripps, P. Karvánková, S. Vepřek, Surf. Coat. Technol. 200 (2006) 5645

[42] H. Bückle, in: J.H. Westbrook, H. Conrad (Eds.), The Science of Hardness testing and its research applications, American Society of Metals, Metals Park, Ohio, 1971, p. 453.

[43] H. Bückle, L'essai de microdureté et ses applications, vol. 90, Publications Scientifiques et Techniques du Ministère de l'Air, Paris, 1960, in French.

[44] O. Vingsbo, S. Hogmark, B. Jönsson, A. Ingemarson, in: P.J. Blau, B.R. Lawn (Eds.), Microindentation Techniques in Materials Science and Engineering ASTM STP 889, American Society for Testing and Materials, Philadelphia, 1986, p. 257.

[45] G. Farges, D. Degout, Thin Solid Films 181 (1989) 365. 
[46] A. Iost, R. Bigot, J. Mater. Sci. 31 (1996) 3573.

[47] D. Beegan, M.T. Laugier, Surf. Coat. Technol. 199 (2005) 32.

[48] E.S. Puchi-Cabrera, Surf. Coat. Technol. 160 (2002) 177.

49] A.M. Korsunsky, M.R. McGurk, S.J. Bull, T.F. Page, Surf. Coat. Technol. 99 (1998) 171.

50] A. Iost, R. Bigot, Surf. Coat. Technol. 80 (1996) 117.

[51] X. Cai, H. Bangert, Thin Solid Films 264 (1995) 59.
52] X.Y. Zhou, Z. Jiang, H. Wang, R. Yu, Mater. Sci. Eng., A 488 (2008) 318

[53] P.A. Engel, E.Y. Hsue, R.G. Bayer, Wear 162/164 (1993) 538.

[54] P.A. Engel, A.R. Chitsaz, E.Y. Hsue, Thin Solid Films 207 (1992) 144.

[55] A. Iost, D. Najjar, R. Hellouin, Surf. Coat. Technol. 165 (2003) 126.

[56] P.-W. Kao, J.G. Byrne, Fatigue Fract. Eng. Mater. Struct. 3 (1981) 271 